\title{
PERCUTANEOUS LEFT VENTRICULAR PUNCTURE IN THE ASSESSMENT OF AORTIC STENOSIS
}

\author{
BY \\ PETER FLEMING AND RONALD GIBSON \\ From the Cardiac Departments, Guy's and the Brompton Hospitals, London
}

(RECEIVED FOR PUBLICATION OCTOBER 13, 1956)

Experience in the selection of patients for aortic valvotomy has shown that two problems commonly arise : first the determination of the severity of the stenosis, and secondly whether the degree of regurgitation is sufficient to preclude successful valvotomy. The clinical aspects of these problems have been discussed recently by Baker and Campbell (1956). The physiological aspects will be considered in this paper.

The best method of determining the degree of obstruction to flow through a stenotic valve is by the simultaneous measurement of the pressure gradient across the valve and the blood flow through the valve orifice. This principle has been successfully applied to the study of pulmonary and mitral stenosis. The study of aortic stenosis has been hindered by the lack of a safe and simple method of obtaining the left ventricular pressure. Apart from the pioneer work of Buchbinder and Katz (1949), the first approach to this problem was made by Björk, Blakemore, and Malmström (1954), who introduced a catheter into the left ventricle through a needle directed percutaneously into the left atrium. The method of direct percutaneous left ventricular puncture has been described recently by Brock, Milstein, and Ross (1956), who discuss the reasons for adopting this technique.

It is the purpose of this paper to present the results of this investigation in the first 28 patients in whom it has been performed and to discuss their significance. The procedure of left ventricular puncture was initiated by Sir Russell Brock, and carried out by Mr. D. N. Ross at Guy's Hospital and by Mr. B. B. Milstein at Brompton Hospital.

It was considered that the degree of valve obstruction in pure aortic stenosis could be assessed by the simultaneous measurement of the cardiac output and of the systolic gradient across the aortic valve. However, in aortic stenosis with regurgitation it is impossible to measure the total amount of blood expelled through the aortic valve during systole (total left ventricular output), because measurement of the cardiac output by the Fick principle determines only the effective left ventricular output. Since the systolic gradient across the aortic valve is dependent upon the total left ventricular stroke output (effective output plus diastolic regurgitant volume), assessment of the degree of valve obstruction in aortic stenosis with regurgitation by this method becomes unreliable when the degree of regurgitation is more than trivial.

\section{MATERIAL}

There were 20 men and eight women in this series and their ages ranged from 15 to 67 years. In all the patients a diagnosis of aortic stenosis had been made and aortic valvotomy was under consideration. In 11 , no diastolic murmur had been heard at any time and they were considered to have pure aortic stenosis. In the remaining 17, an aortic diastolic murmur was present with or without other clinical evidence of aortic regurgitation; they were regarded as having aortic stenosis with a variable, often unknown, degree of regurgitation. Two patients (Cases 6 and $20^{*}$ ) in the latter group had concomitant mitral stenosis and one patient (Case 12) was found to have subvalvar aortic stenosis at operation.

Eighteen patients have been submitted to aortic valvotomy and this group has been subjected to detailed analysis. Of the remaining 10 cases, valvotomy has been advised in one but has not yet been carried out and was considered to be contraindicated in nine.

\section{METHODS}

The patient was placed in the supine position and the head was supported by one or two pillows; a needle was then inserted into one or other brachial artery and the intra-arterial pressure continuously recorded; a second needle was then inserted through the chest wall into the left ventricle and the intra-

* The case numbers in this paper do not correspond to those in the paper by Brock and others (1956). 
ventricular and arterial pressures recorded either simultaneously (Fig. 5) or in immediate succession (Figs. 3 and 4). With the sternal angle as reference point, pressures were recorded by means of one or two capacitance electromanometers (Sanborn or Southern instruments) and direct - writing recorders (Sanborn or Brush). When one manometer only was used, pressures were recorded in immediate succession, using a three-way tap (Epps and Adler, 1953). No damping was employed, other than the needle damping. In 17 cases catheterization of the right heart was carried out for the determination of the cardiac output simultaneously with the recording of the left ventricular and brachial arterial pressures. Oxygen uptake was estimated by measurement and analysis of the expired air or by spirometry (Donald and Christie, 1949), and the arterio-venous oxygen difference determined by analysis of the brachial arterial and mixed venous (pulmonary arterial) blood samples, using the methods of Haldane (Courtice and Douglas, 1947) or of Van Slyke (Peters and Van Slyke, 1932).

The use of the brachial arterial pressure pulse in this study introduces a possible error in the measurement of the systolic gradient across the aortic valve, and it would have been preferable to have used the aortic pressure pulse. However, it has been shown by Wright, Toscano-Barboza, and Brandenburg (1956) that the form of the central pressure pulse is trans- mitted to the periphery more faithfully in aortic stenosis than in the normal. Our own observations on simultaneous aortic and brachial arterial pressure pulses recorded at operation for aortic stenosis confirm this (Fig. 6). We consider that any error introduced by the use of the brachial arterial pressure pulse is not significant. Therefore the brachial arterial pressure pulse was used to avoid the additional hazards of aortic catheterization.

\section{RESULTS}

The relevant data on all the patients investigated by this technique are summarized in Table $I$. The operated cases are arranged in grades according to the estimate of the size of the aortic valve orifice made by the surgeon at operation; thus, in the two patients in Grade $I$, the valve orifice was probably larger than $1 \mathrm{sq} . \mathrm{cm}$., and, in those in Grade IV, less than 0.25 sq. cm. : Grades II and III are intermediate groups. It should be emphasized that the surgical estimate, made by consideration of the degree of mobility of graduated bougies in the valve orifice, is not sufficiently accurate to permit a precise numerical statement of the valve size for each individual (Brock, personal communication).

TABLE I

HAEMODYNAMIC STUDIES IN 28 CASES OF AORTIC STENOSIS

\begin{tabular}{|c|c|c|c|c|c|c|c|c|c|c|c|c|c|c|c|c|c|c|c|c|c|}
\hline \multirow[b]{2}{*}{$\begin{array}{l}0 \\
\mathbf{z} \\
: \\
\tilde{z} \\
0\end{array}$} & \multirow[b]{2}{*}{ 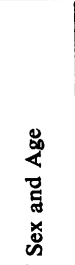 } & \multirow[b]{2}{*}{ 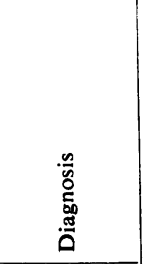 } & \multirow{2}{*}{ 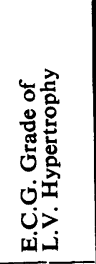 } & \multicolumn{2}{|c|}{$\begin{array}{c}\text { L.V. } \\
\text { Pressure } \\
\text { (mm. Hg) }\end{array}$} & \multicolumn{3}{|c|}{$\begin{array}{c}\text { B.A. } \\
\text { Pressure } \\
(\mathbf{m m} . \mathrm{Hg})\end{array}$} & \multirow{2}{*}{ 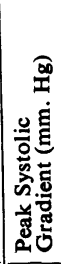 } & \multirow{2}{*}{ 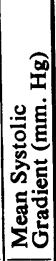 } & \multirow{2}{*}{ 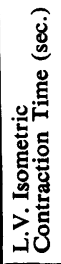 } & \multirow[b]{2}{*}{ 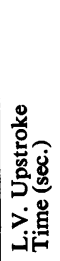 } & \multirow{2}{*}{ 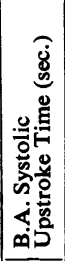 } & \multirow{2}{*}{ 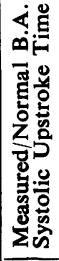 } & \multirow[b]{2}{*}{ 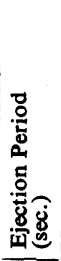 } & \multirow{2}{*}{ 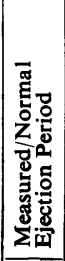 } & \multirow[b]{2}{*}{ 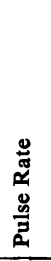 } & \multirow{2}{*}{ 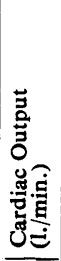 } & \multirow{2}{*}{ 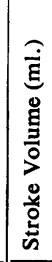 } & \multirow{2}{*}{ 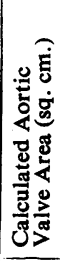 } & \multirow{2}{*}{ 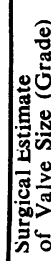 } \\
\hline & & & & 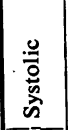 & 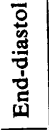 & 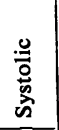 & 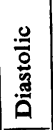 & 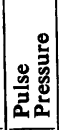 & & & & & & & & & & & & & \\
\hline $\begin{array}{l}1 \\
2 \\
3 \\
4\end{array}$ & $\begin{array}{ll}M & 35 \\
M & 30 \\
F & 26 \\
M & 41 \\
M & 47 \\
F & 47 \\
M & 30 \\
M & 47 \\
M & 40 \\
M & 16 \\
M & 15 \\
M & 16 \\
M & 34 \\
M & 43 \\
M & 33 \\
M & 55 \\
M\end{array}$ & $\begin{array}{l}\text { AR } \\
\text { AR } \\
\text { AR } \\
\text { AR, MS } \\
\text { AR } \\
\text { AR } \\
\text { AR }\end{array}$ & $\begin{array}{r}\text { III } \\
\text { II } \\
\text { III } \\
\text { II } \\
\text { II } \\
\text { II } \\
\text { IV } \\
\text { II }\end{array}$ & $\begin{array}{l}24 \\
23 \\
14 \\
22 \\
14 \\
16 \\
15 \\
22 \\
16 \\
17 \\
25 \\
22 \\
26\end{array}$ & $\begin{array}{r}15 \\
15 \\
5 \\
10 \\
5 \\
5 \\
10\end{array}$ & $\begin{array}{r}130 \\
95 \\
100 \\
100 \\
80 \\
115 \\
110 \\
130 \\
95 \\
130 \\
100 \\
80 \\
150 \\
100 \\
115 \\
140 \\
95 \\
\end{array}$ & $\begin{array}{l}6 \\
6 \\
4 \\
5\end{array}$ & $\begin{array}{l}80 \\
40 \\
30 \\
40 \\
5 \\
2 \\
40 \\
30 \\
6 \\
3 \\
4 \\
4 \\
3 \\
8 \\
4 \\
3 \\
6 \\
5 \\
\end{array}$ & $\begin{array}{r}60 \\
100 \\
45 \\
120 \\
45 \\
80 \\
35 \\
110 \\
35 \\
75\end{array}$ & \begin{tabular}{|r}
43 \\
62 \\
40 \\
97 \\
28 \\
65 \\
30 \\
77 \\
25 \\
107 \\
107 \\
90 \\
70 \\
66 \\
159 \\
159 \\
45 \\
52 \\
\end{tabular} & & & 10.26 & $\begin{array}{l}2.2 \\
1.8 \\
2.4 \\
2.0 \\
2.1 \\
2.0 \\
1.9\end{array}$ & 036 & 1.2 & & $\begin{array}{r}7.3 \\
5.9 \\
12.9 \\
4.7 \\
4.3 \\
\\
5.7\end{array}$ & $\begin{array}{c}56 \\
51 \\
132 \\
84 \\
60 \\
\overline{-} \\
\overline{57} \\
63 \\
55 \\
55 \\
\frac{}{二} \\
\frac{88}{二} \\
\end{array}$ & $\begin{array}{r}0.58 \\
\overline{-} \\
0.85 \\
0 . \overline{46} \\
0.45 \\
\bar{Z} \\
\overline{0} \\
=\overline{52} \\
\end{array}$ & \\
\hline 19 & $\begin{array}{ll}\mathbf{F} & 42 \\
M & 39 \\
M & 35 \\
F & 50 \\
F & 42 \\
F & 45 \\
F & 42 \\
F & 42 \\
M & 67 \\
M & 42\end{array}$ & $\begin{array}{l}\mathbf{R} \\
\mathbf{R} \\
\mathbf{R} \\
\mathbf{R} \\
\mathbf{R} \\
\mathbf{R}\end{array}$ & $\begin{array}{r}\text { II } \\
\text { III } \\
\mathbf{0} \\
\mathbf{I} \\
\mathbf{I} \\
\mathbf{0} \\
\mathbf{I} \\
\text { II } \\
\text { IHD } \\
\mathbf{W}-\mathbf{P}-\mathbf{W}\end{array}$ & $\begin{array}{l}190 \\
100 \\
105 \\
185 \\
125 \\
100 \\
165 \\
240 \\
145 \\
140\end{array}$ & \begin{tabular}{|r|}
20 \\
0 \\
5 \\
10 \\
5 \\
$?$ \\
15 \\
20 \\
10 \\
15
\end{tabular} & $\begin{array}{l}125 \\
55 \\
105 \\
125 \\
110 \\
100 \\
155 \\
200 \\
155 \\
125\end{array}$ & \begin{tabular}{|r|}
70 \\
25 \\
65 \\
70 \\
45 \\
70 \\
80 \\
100 \\
75 \\
55
\end{tabular} & \begin{tabular}{|r|}
55 \\
30 \\
40 \\
55 \\
65 \\
30 \\
75 \\
100 \\
80 \\
70
\end{tabular} & $\begin{array}{r}60 \\
15 \\
0 \\
10 \\
40 \\
0 \\
15\end{array}$ & $\begin{array}{r}23 \\
31 \\
0 \\
49 \\
0 \\
30 \\
0 \\
10\end{array}$ & $\begin{array}{l}0.08 \\
0.05\end{array}$ & $\begin{array}{l}0.16 \\
0.2 \\
0.22\end{array}$ & 0.22 & \begin{tabular}{|l|}
2.4 \\
1.2 \\
1.1 \\
1.6 \\
2.0 \\
1.5 \\
1.6 \\
1.8 \\
1.5 \\
1.8
\end{tabular} & $\cdot 34$ & $\begin{array}{l}1.3 \\
1.3\end{array}$ & & $\begin{array}{r}4.8 \\
6 \cdot 0 \\
102 \\
8 \cdot 3 \\
\overline{5.0} \\
\frac{-}{4.8} \\
7 \cdot 1\end{array}$ & $\begin{array}{r}48 \\
85 \\
127 \\
86 \\
67 \\
7 \\
80 \\
99\end{array}$ & $\bar{Z}=$ & $\begin{array}{l}\bar{Z} \\
\bar{z}\end{array}$ \\
\hline
\end{tabular}

AS $=$ aortic stenosis. $\quad \mathbf{A R}=$ aortic regurgitation. $\mathbf{M S}=$ mitral stenosis. $\mathbf{I H D}=$ ischaemic heart disease.

Cases $1-18=$ operated cases. Cases $19-28=$ non-operated cases. 
Left Ventricular Pressure Pulse

Acceptable left ventricular pressure records (Fig. 2) were obtained in all cases with one exception (Case 24) in which the curves were considered to be over-damped. The recorded left ventricular diastolic pressure was the end-diastolic level just before the systolic upstroke (Figs. 1 and 2 ). The isometric contraction time was measured from the onset of the left ventricular systolic upstroke to the point at which it reached the level of the end-diastolic pressure in the brachial artery (Fig. 1). The left ventricular upstroke time was measured from the end of the isometric contraction period to the systolic peak of the left ventricular pressure pulse.

Brachial Arterial Pressure Pulse

Acceptable intra-arterial pressure pulses were recorded in all but four cases; in these, the arterial pressure was measured by sphygmomanometry. The systolic upstroke time was measured from the beginning of the upstroke to the peak of the tidal wave. The predicted normal upstroke time was calculated from the formula

Normal upstroke time $=1 / \sqrt{\text { pulse rate }}$

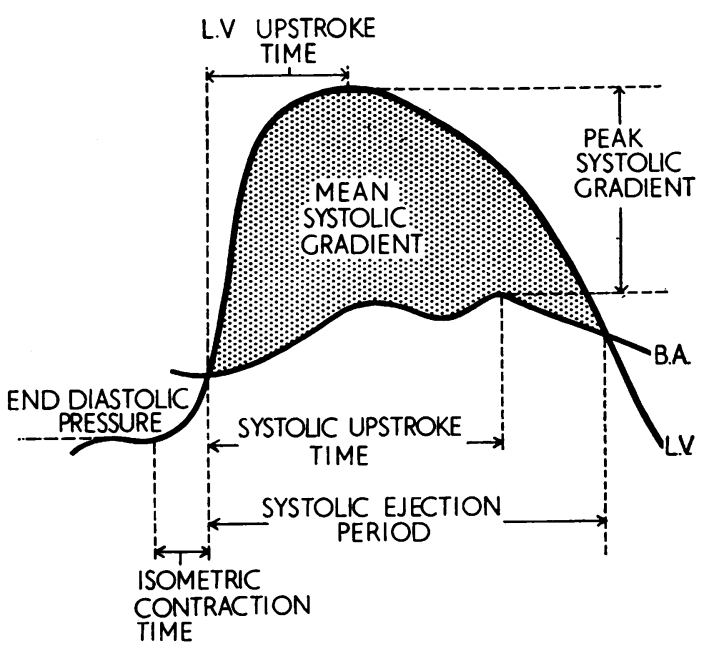

FIG. 1.-Diagram of superimposed left ventricular and brachialarterial pressure pulses illustrating the measurements described in the text.

(Macdonald, Shanks and Smith, 1956) and the ratio measured upstroke time/normal upstroke time was calculated.

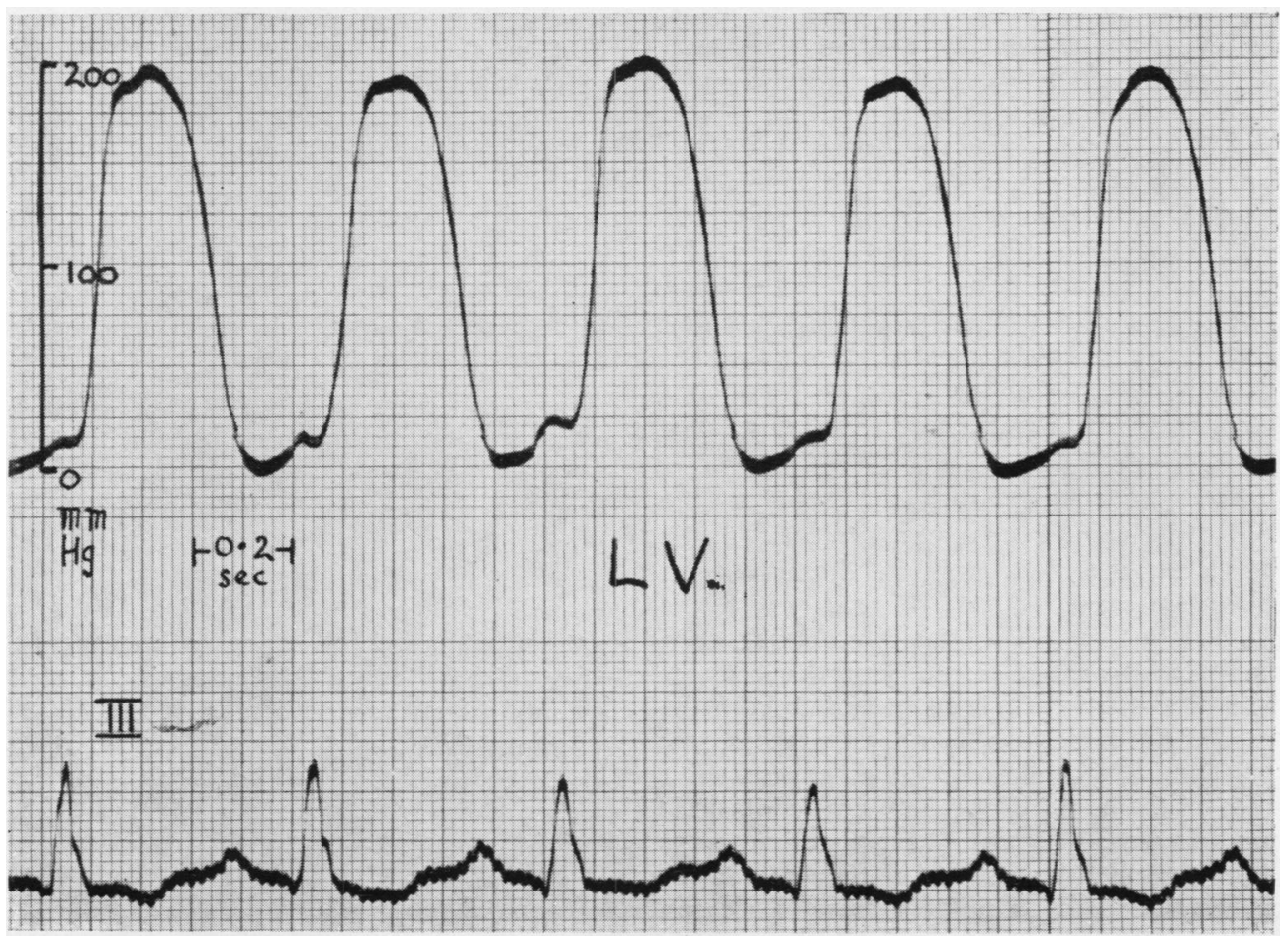

FIG. 2.-Left ventricular pressure pulse in a case of aortic stenosis showing elevation of the systolic and end-diastolic pressures and the steep left ventricular upstroke. 


\section{Aortic Systolic Gradients}

The peak systolic gradient has been calculated by simple subtraction of the brachial systolic from the left ventricular systolic pressure, and the mean systolic gradient by planimetric integration of the superimposed left ventricular and brachial arterial pressure pulses (Fig. 1).

\section{EJeCtion Period}

This was measured directly from the superimposed curves. The normal ejection period for the cycle length in each case was calculated from the formula

Ejection period $=0.31 \sqrt{\text { cycle length }}-0.05$

(modified from Katz and Feil, 1925) and the ratio measured ejection period/normal ejection period has also been calculated.

\section{Aortic Valve Area}

This was calculated using the formula of Gorlin and Gorlin (1951).

\section{DISCUSSION}

Before consideration of the operated cases, a brief discussion of the 10 cases not operated upon is necessary. In Case 19 , in which there is no evidence of aortic regurgitation, aortic valvotomy has been advised. In Cases $21,23,24$, 25,27 , and 28 , the peak systolic gradient ranged from 0 to $15 \mathrm{~mm}$. $\mathrm{Hg}$ and it is thought that such aortic stenosis as exists is not haemodynamically significant. Cases 20 and 26, despite peak systolic gradients of 40 to $45 \mathrm{~mm} . \mathrm{Hg}$, are regarded on clinical grounds as suffering from dominant aortic regurgitation and the same conclusion has been reached in Case 22 as a result of the findings at left ventricular puncture (see below).

We have confined our attention largely to the patients who have been submitted to aortic valvotomy, because it is only in these that an objective assessment of the degree of aortic stenosis is available. There was some doubt, even at operation, as to the degree of stenosis in Cases 17 and 18, and they have been excluded from the analysis. Of the remaining 16 operated cases, two (Cases 1 and 2) had distinctly larger valve orifices than the rest. Both had aortic diastolic murmurs and were at least as severely disabled as the other operated cases. As the degree of stenosis was found to be mild in these two cases, the inference we have drawn is that aortic regurgitation was dominant.
The Left Ventricular Pressure Pulse

In the absence of direct recordings of left ven- $\frac{\bar{O}}{\bar{\sigma}}$ tricular pressure pulses in man, most previous $\frac{\overline{\bar{D}}}{\overline{5}}$ work on the dynamics of left ventricular systole $\mathbb{\Phi}$ in aortic stenosis has involved indirect methods of study. The effects of constriction of the aorta ${ }^{\infty}$ just above the valve have been studied as an acute $\vec{\circ}$ experiment in animals, and in the human subject $\overrightarrow{\vec{\omega}}$ cardiac events have been timed by means of $\mathscr{N}$ phonocardiography and simultaneous arterial $\vec{\sim}$ pulse tracings. The available evidence has been $\stackrel{x}{-}$ summarized by Wiggers (1952). We propose to $\vec{N}$ discuss our findings in the 14 patients in whom $\vec{\omega}$ the surgeon's estimate of the aortic valve size was $v$ not more than $1 \mathrm{sq}$. $\mathrm{cm}$. (Grades II-IV), regarding $ᄋ$ these patients as suffering from pure or dominant aortic stenosis. Seven of these patients, in fact, $\frac{3}{\mathrm{t}}$ had aortic diastolic murmurs, but in none of these was the valve larger than about $0.6 \mathrm{sq} . \mathrm{cm}$. The ${ }_{-}$ remaining seven had no evidence of aortice regurgitation, including Cases 3 and 4 with valves.. of about 1 sq. $\mathrm{cm}$. All these 14 patients were more or less severely disabled and it is considered that they represent a homogeneous group.

END-DIASTOLIC Pressure.-All the patients were in sinus rhythm and a small positive wave was almost constantly present just before the main $\overrightarrow{\overrightarrow{0}}$ upstroke of left ventricular systole, representing 3 the "a" wave of left atrial systole. This varied? in height from 5 to $40 \mathrm{~mm}$. $\mathrm{Hg}$ and tended to be higher in the patients with the highest left ventricular systolic pressures, although this was by no means constant. In the two patients (Cases $13 x$ and 14) with an end-diastolic pressure of 25 and $40 \mathrm{~mm}$. $\mathrm{Hg}$ there was clinical evidence of lef ventricular failure at the time of the investigation?

Left Ventricular Systolic Pressure.-Theo most striking feature of the left ventricular response to significant aortic stenosis is the development of a high systolic pressure. The lef ventricular pressure pulse becomes more sharply peaked than normal, and approaches the form of an isometric type of contraction. In these 140 patients the left ventricular systolic pressure ranged from 140 to $325 \mathrm{~mm}$. Hg. In the two patients in left ventricular failure it was 200 an $260 \mathrm{~mm}$. Hg.

Phases of Systole.-These are the isometric contraction time, the ejection period, and the lefe् ventricular upstroke time.

(a) Isometric Contraction Time.-The norma $\$$ isometric contraction time of the left ventricle i\% given as $0.05 \mathrm{sec}$. by Wiggers (1949) and is saif 


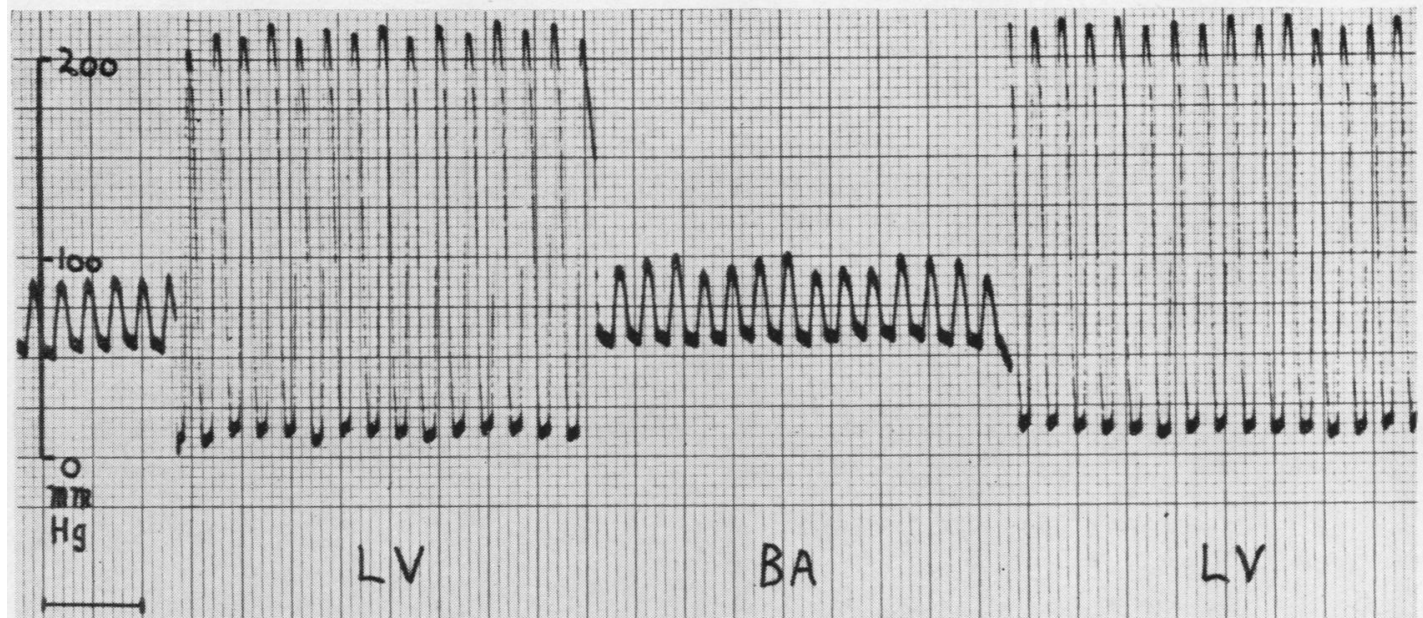

$2 \mathrm{sec}$

FIG. $3 a$

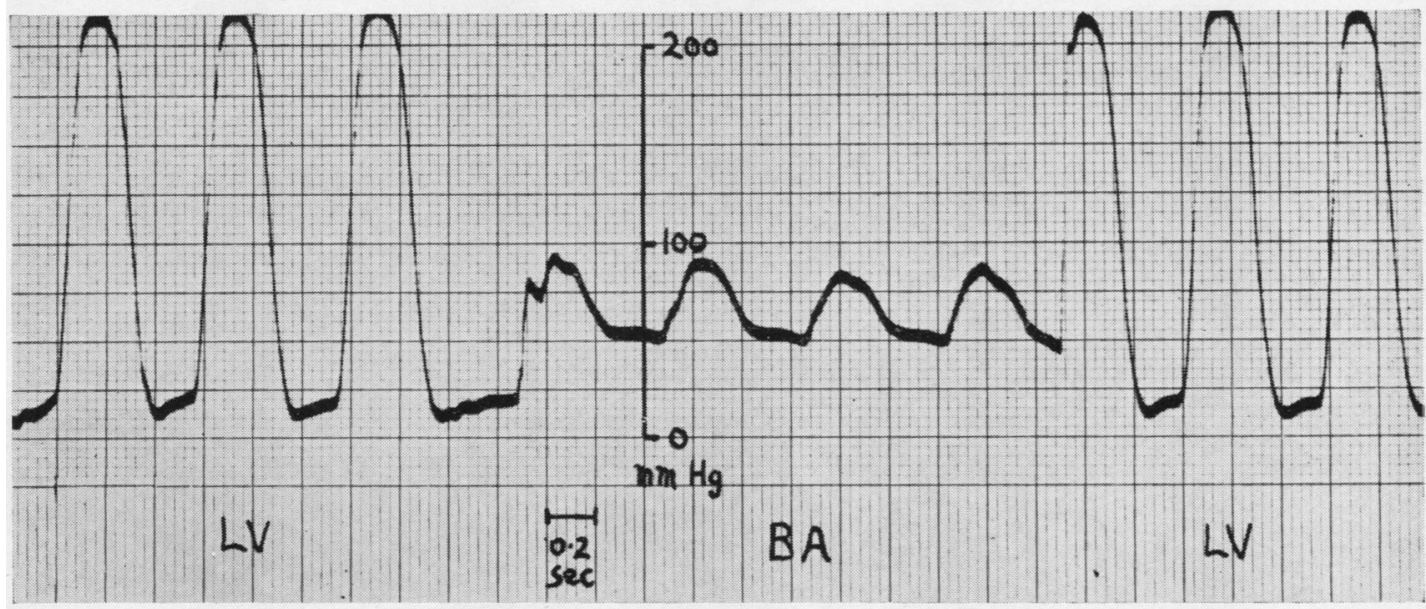

FIG. $3 b$

Fig. 3.-Left ventricular and brachial arterial pressure pulses recorded in immediate sucoession in a case of severe aortic stenosis, showing a peak systolic gradient of $120 \mathrm{~mm}$. Hg. (a) Paper speed $5 \mathrm{~mm}$. per sec. (b) Paper speed $25 \mathrm{~mm}$. per sec. 


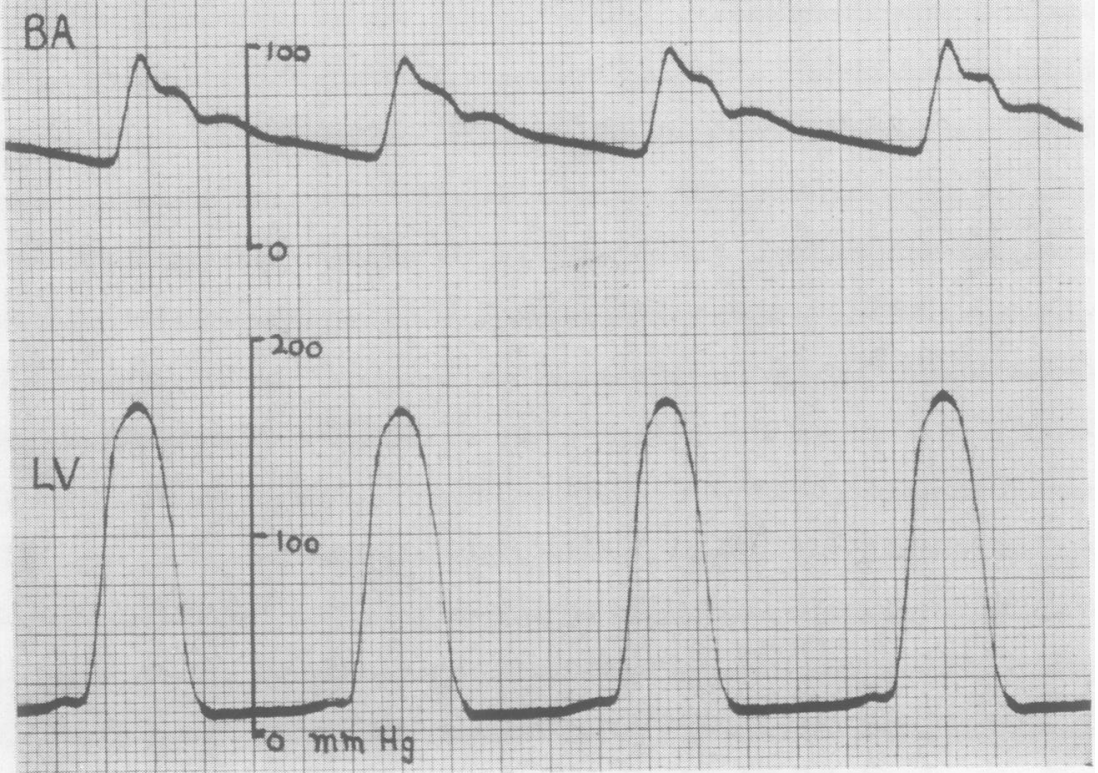

FIG. 4.-Left ventricular and $\frac{\sigma}{3}$ brachial arterial pressure $\underline{3}$. pulses recorded in immediate succession in a case of mild aortic stenosis with regurgitation, showing a peak 은 systolic gradient ranging from 5 to $15 \mathrm{~mm}$. $\mathrm{Hg}$.

Fig. 5.-Simultaneous left ventricular and brachial arterial 0 aortic stenosis with regurgi- $c$ tation, showing a peak $\frac{}{(D}$ systolic gradient of $70 \stackrel{\infty}{\rightarrow}$ mm. Hg. 


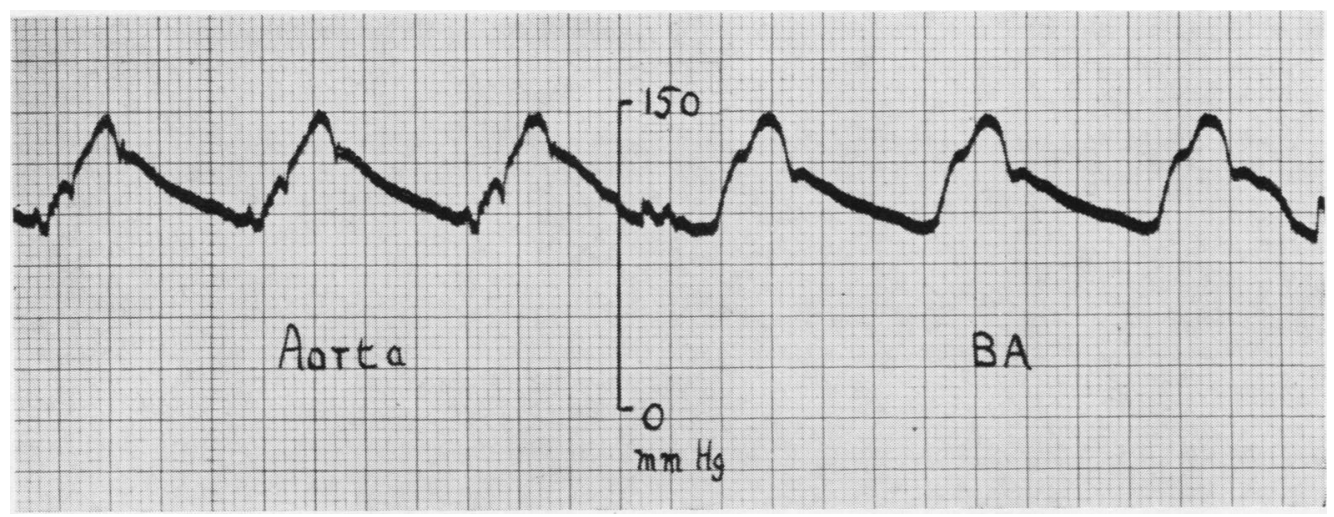

FIG. 6.-Aortic and brachial arterial pressure pulses recorded in immediate succession during thoracotomy in a case of aortic stenosis, showing similar systolic and diastolic pressures in the aorta and brachial artery.

to be little influenced by changes in pulse rate. Two of our patients had isometric contraction times of $0.06 \mathrm{sec}$. and one of $0.05 \mathrm{sec}$; in the remaining 11 it was below normal, values of 0.02 sec. being found in three patients. We also found that there was an inverse relationship between the length of the isometric contraction time and the peak systolic gradient (Fig. 7). This finding of an abnormally short isometric contraction time is in agreement with the observations of Katz, Ralli, and Cheer (1928) but is at variance with other work on experimental aortic stenosis in dogs in which the isometric period was reported to be prolonged (Wiggers, 1952). We suggest that the explanation of this discrepancy is that, in experimental animals, the obstruction is placed on the aorta just above the valve. The situation is therefore similar to that in coarctation of the aorta in that there is a high pressure just distal to the valve which does not open until the left ventricular pressure has reached a correspondingly high level. In clinical aortic stenosis, the

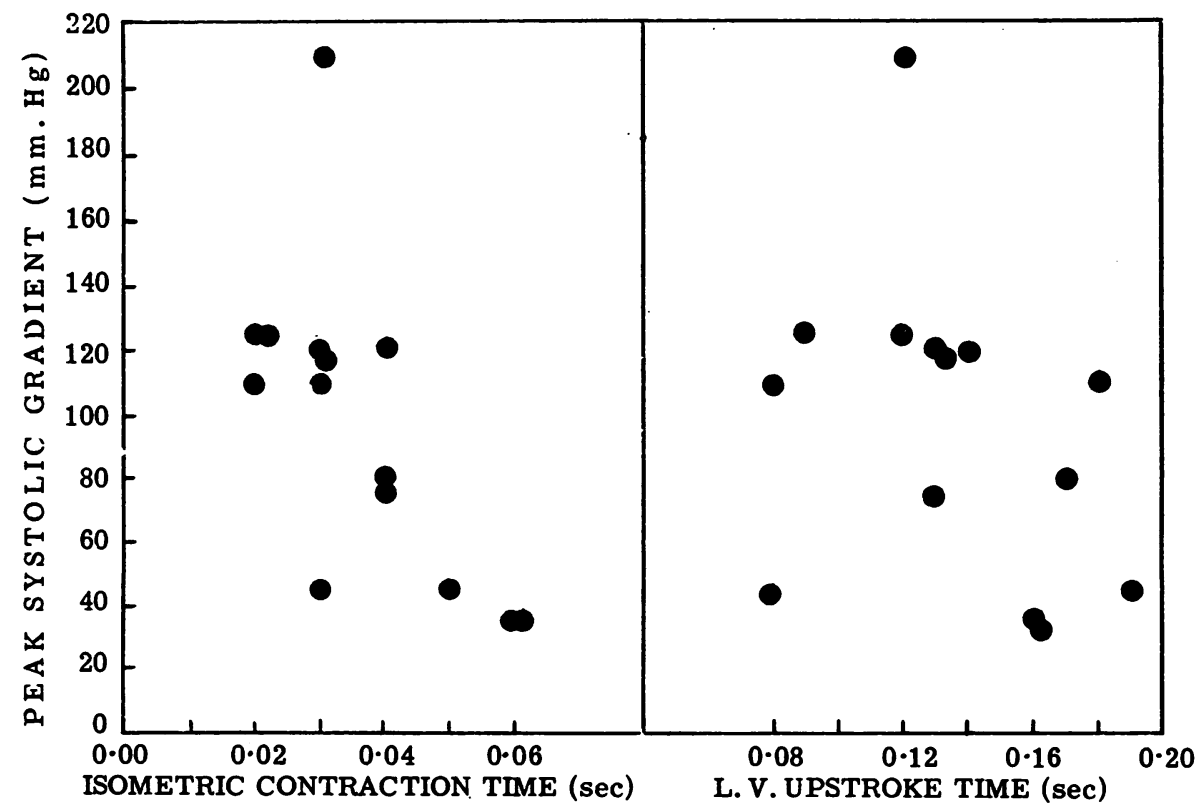

Fig. 7.-Relationship of the peak systolic gradient to the left ventricular isometric contraction and upstroke times in the 14 cases of aortic stenosis proved at operation. 
diastolic pressure distal to the valve is not raised and ejection begins at a lower and earlier point on the left ventricular pressure pulse.

(b) Ejection Period.-All previous workers (Wiggers, 1949 ; Katz and Feil, 1925 ; Katz and others, 1928) have emphasized a consistent lengthening of the ejection period of the left ventricle in aortic stenosis: this has recently received clinical confirmation by the demonstration of paradoxical splitting of the second heart sound (Gray, 1956). The ejection period was prolonged in all our cases; Fig. 8 contrasts the measured ejection periods with the normal values at different pulse rates. Katz and Feil (1925) found that the ejection period was not prolonged in left ventricular failure due to aortic stenosis and our two patients in left ventricular failure had rather shorter ejection periods than others of comparable severity.

(c) Left Ventricular Upstroke Time.-Katz and others (1928) found in dogs that, as the degree of constriction of the ascending aorta increased, the peak of the left ventricular pressure pulse was often reached earlier. In our cases the time from the beginning of ejection to the left ventricular systolic peak ranged from 0.08 to $0.19 \mathrm{sec}$. We have been unable to find any figures in the literature for the range of normal for this phase of systole, but study of the chart published by Wiggers (1952) showing the phases of the cardiac $\cong$ cycle suggests that this phase, termed by him the maximum ejection phase, normally occupies rather $\vec{\circ}$ more than half of the total ejection period. In the majority of our cases it was of relatively shorter $\vec{\omega}$ duration and, more significantly, we found that, $\stackrel{\circ}{\circ}$ with a few exceptions, its length was inversely $\vec{x}$ proportional to the peak systolic gradient (Fig. 7). $\vec{N}$ It seems, therefore, that the prolonged ejection period in these cases is due entirely to a prolongation of the time from the left ventricular systolic 0 peak to the end of ejection-the phase of reduced ejection (Wiggers, 1952).

LefT Ventricular Work.-Gorlin, McMillan, Medd, Matthews, and Daley (1955) calculated $\stackrel{?}{\mathcal{S}}$ total left ventricular work for some of their cases $\vec{G}$ of aortic stenosis, investigated post mortem by the $v$ McMillan pump system (McMillan, Daley, and Matthews, 1952). The formula they used (flow $\times$ pressure) estimates the potential energy of the ventricle only. In normal subjects at rest, it is

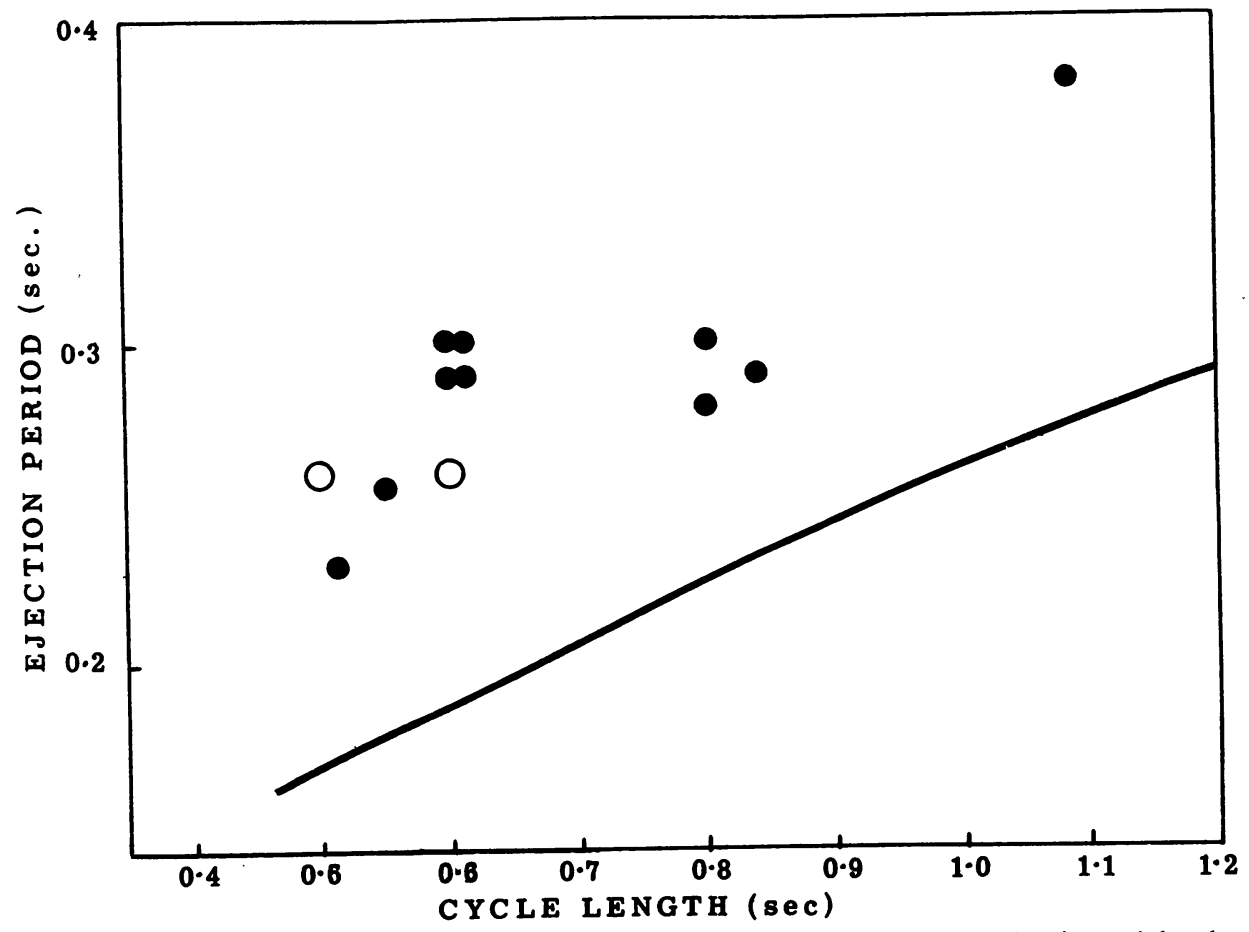

FIG. 8.-Left ventricular ejection period in 12 cases of aortic stenosis proved at operation plotted against cycle length. The open circles represent cases of left ventricular failure. The line illustrates the normal relationship between ejection period and cycle length (Katz and Feil, 1925). 
probable that this component comprises nearly all of the total left ventricular work. In aortic stenosis, however, when the blood is ejected into the aorta at a very high velocity, the kinetic component of left ventricular work is no longer insignificant. For the determination of the velocity of blood-flow, it is necessary to know the exact cross-sectional area of the aortic valve orifice. We have used the calculated aortic valve area to estimate the flow velocity in some of our patients and have obtained figures for the potential and kinetic components of left ventricular work; the kinetic component varied from $11 \%$ to $31 \%$ of the total work, compared with 0.5 to $1 \%$ for normal subjects at rest. However, it is considered that the accuracy of the raw data is not great enough to allow us to draw any valid conclusions from figures for left ventricular work obtained by this means.

\section{Assessment of Severity of Aortic Stenosis}

Most previous workers on this subject have classified cases of aortic stenosis according to the anatomical degree of stenosis found at necropsy (Kumpe and Bean, 1948 ; Lewes, 1951 ; Bergeron, Abelmann, Vazquez-Milan and Ellis, 1954). In this series a similar criterion has been adopted, namely the surgeon's estimate of the size of the valve orifice at operation. The decision to use this anatomical criterion was taken after a preliminary study of the results. This study showed that, if significant aortic regurgitation is present, the left ventricular systolic pressure can be over $200 \mathrm{~mm}$. $\mathrm{Hg}$ in the presence of a mild anatomical degree of stenosis. Even in pure aortic stenosis, the interrelationships of systolic gradient, stroke volume, and ejection period were too complex to permit the use of any one of these variables in isolation as a criterion of severity. Therefore it is proposed in this section to compare various parameters with the surgeon's estimate of the size of the valve, in the 16 cases in which it is available. In addition, we shall discuss the significance of the ejection period and brachial arterial upstroke time in both operated and non-operated cases.

Peak Systolic Gradient.-The systolic gradient across the aortic valve is regularly measured immediately before and after aortic valvotomy to assess the efficacy of the procedure, and it might seem at first sight to be a useful index of the size of the aortic valve orifice for the comparison of one individual with another. Fig. 9, illustrating the comparison between the peak systolic gradient and the valve size estimated at operation, shows that this is not so, and that a gradient of over $100 \mathrm{~mm}$. $\mathrm{Hg}$ may be recorded at left ventricular puncture when the valve is less than 0.25 sq. $\mathrm{cm}$. or more than 1 sq. $\mathrm{cm}$. These variations must be due to differences in stroke volume: Case 4 , with a valve orifice of about 1 sq. $\mathrm{cm}$., and a peak systolic gradient of $120 \mathrm{~mm}$. $\mathrm{Hg}$, had a stroke volume of $132 \mathrm{ml}$.; in the other cases with a large gradient and a relatively large valve orifice (over 1 sq. $\mathrm{cm}$.) there was evidence of aortic regurgitation which must have been severe enough to produce a considerable increase in stroke volume. Gorlin and others (1955) have claimed that a high systolic gradient could occur in patients with significant aortic regurgitation: we have demonstrated a peak systolic gradient of $100 \mathrm{~mm}$. $\mathrm{Hg}$ in such a case (Case 2). There seems no theoretical reason why an even higher gradient should not occur, if the regurgitant volume is large, but, in this series, all the patients with a peak systolic gradient of 120 $\mathrm{mm}$. $\mathrm{Hg}$ or over had dominant aortic stenosis.

EJection Period.-This can be measured from a phonocardiogram and it would have been extremely valuable if it had been found to be related to the size of the valve orifice. Although, as we have pointed out, it was invariably prolonged in our cases, the degree of prolongation bore no relation to the size of the valve orifice, even if pulse rate variations were eliminated by expressing it as a fraction of the normal ejection period for cycle length. It is probable that, in this case also, variations in stroke volume prevent a better correlation, as Katz and Feil (1925) have shown that a large stroke volume, as in aortic regurgitation, is associated with prolongation of the ejection period, even in the absence of aortic stenosis. This has received confirmation from the finding by Gray (1956) of phonocardiographic evidence of prolongation of left ventricular systole in patent ductus arteriosus, in which condition the left ventricular stroke volume is abnormally large. There was also considerable prolongation of the ejection period in some of the non-operated cases with a trivial gradient (e.g., Cases 23 and 25) and it seems that prolongation of ejection is an earlier manifestation of the left ventricular response to aortic stenosis than the development of a high systolic pressure and a systolic gradient across the valve.

Brachial Arterial Pressure Pulse.-The small pulse pressure of aortic stenosis is no longer regarded as a reliable criterion of severity (Kumpe and Bean, 1948 ; Lewes, 1951). A wide pulse pressure was found in cases of both mild and severe stenosis in this series (Fig. 9); however, our findings suggest that a pulse pressure below 40 $\mathrm{mm}$. $\mathrm{Hg}$ is a point in favour of severe stenosis. 

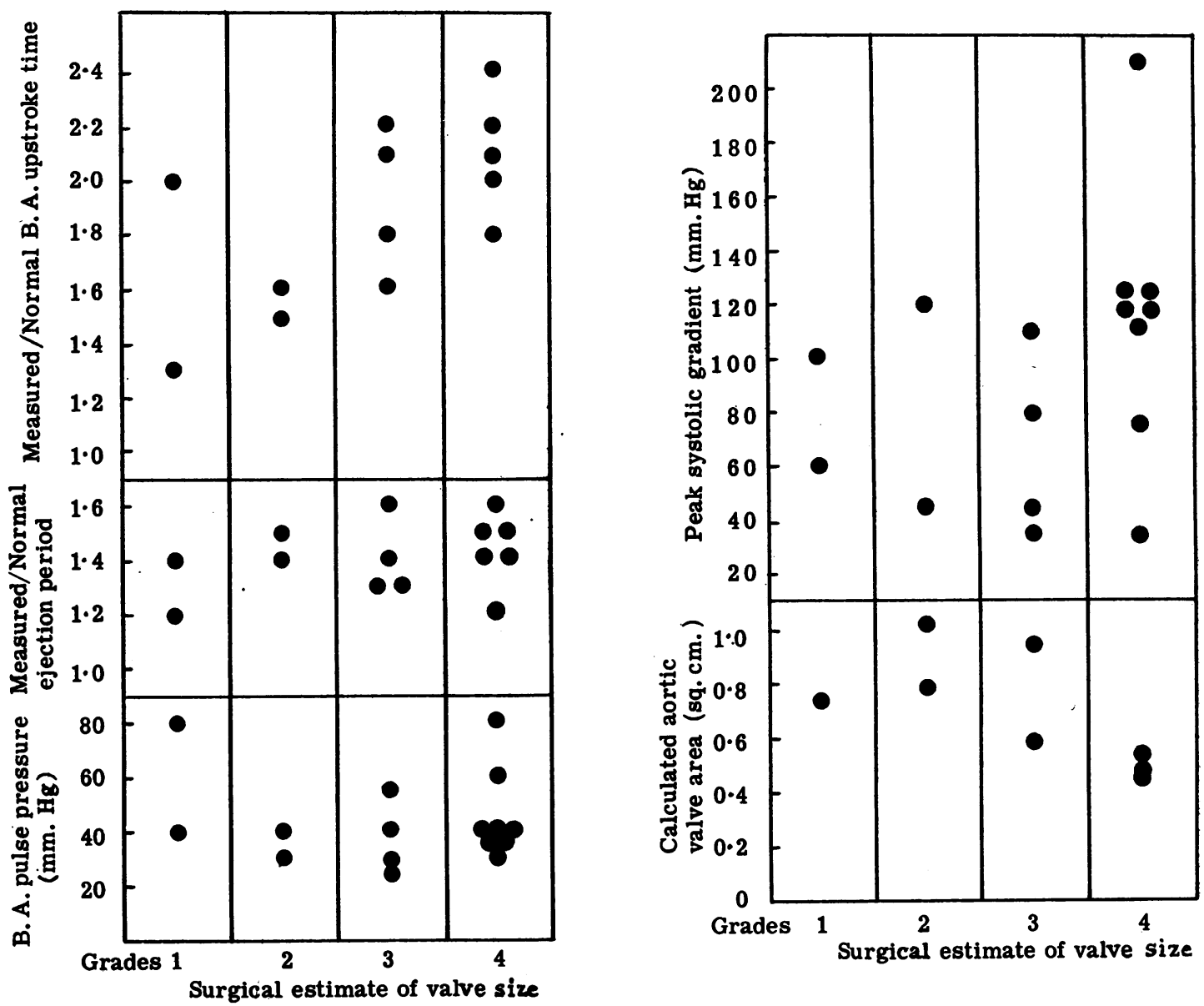

FIG. 9.-Relationship of the surgical estimate of the valve size to the brachial arterial pulse pressure, the measured/normal ejection period, the measured/normal brachial arterial upstroke time, the calculated aortic valve area, and the peak systolic gradient in operated cases, excluding Cases 17 and 18 in which the valve size could not be estimated at operation.

The upstroke time of the brachial arterial pressure pulse has been used as a quantitative expression of the slow-rising pulse of aortic stenosis (Goldberg, Bakst, and Bailey, 1954 ; Gorlin and others, 1955). We have measured the upstroke time to the peak of the tidal wave, even if it was lower than the percussion wave. But there is some evidence (Fleming, 1956) that, in a bisferiens type of pulse, neither percussion nor tidal wave represents the true systolic peak which is obliterated by the Venturi effect of the high-velocity blood stream. In an anacrotic type of pulse, however, the tidal wave can be regarded as a close approximation to the true systolic peak. A fair degree of correlation has been found between the surgical estimate of the valve size and the systolic upstroke time expressed as a fraction of the normal upstroke time. The relationship is illustrated in Fig. 9. Two patients only, of those represented in this graph, $\mathrm{O}$ had a bisferiens type of pulse (Cases 2 and 13), and in both the systolic upstroke time was considerably longer than in other cases of comparable severity. These discrepancies can be explained by regarding 0 the tidal wave in such cases as a point on the $N$ downstroke of a wave whose peak has been $N$ obliterated. Prolongation of the systolic upstroke time was also found in all the non-operated cases, suggesting that this is a very early manifestation of aortic stenosis.

Aortic Valve ARea.-The interrelationship 0 between systolic gradient, stroke volume, and ejection period has already been emphasized. $\stackrel{\mathbb{D}}{\circ}$ The aortic valve area, calculated from the for- $\overrightarrow{\mathbb{D}}$ mula of Gorlin and Gorlin (1951), combines all $\cong$ these variables and its relationship to the surgical estimate of the size of the valve is shown in Fig. 9. 
The two estimates are rarely identical, and, in dominant stenosis, the calculated value tends to over-estimate the size of the valve. The correlation is sufficiently close, however, to convince us that, provided there is no significant degree of aortic regurgitation, the calculated aortic valve area gives a reasonable estimate of the degree of aortic stenosis. This finding emphasizes the importance of determining the cardiac output in conjunction with measurement of the systolic gradient if a reliable assessment of the degree of aortic stenosis is to be obtained.

If significant aortic regurgitation is present, the figure obtained for the aortic valve area is an under-estimate because the cardiac output, measured by the Fick principle, is less than the total left ventricular output. This is illustrated by Case 2, in which the calculated aortic valve area was 0.73 sq. $\mathrm{cm}$.; at operation the valve was found to be larger than 1 sq. $\mathrm{cm}$. Provided this source of error is borne in mind, however, the calculation of the aortic valve area is not without value even if significant aortic regurgitation is suspected. In Case 22, there is clinical evidence of aortic regurgitation, but some doubt as to its severity. The calculated aortic valve area is $1.11 \mathrm{sq} . \mathrm{cm}$. which, by comparison with our other figures, represents quite a mild degree of stenosis and, as the true valve area is almost certainly larger than this, it seems probable that stenosis is not the dominant lesion in this case. We would tentatively suggest that if, in a case where the degree of aortic regurgitation is in doubt, the calculated aortic valve area is more than $1 \mathrm{sq}$. cm., aortic stenosis is not severe enough to require valvotomy.

\section{The Significance of the Electrocardiogram}

The electrocardiogram is widely used as an objective indication of severity in aortic stenosis. It was decided, therefore, to compare the electrocardiographic findings with the physiological data and the surgical estimate of the aortic valve size. All the patients in this series (both operated and non-operated cases), with two exceptions, were divided into five grades (0-IV) according to the degree of left ventricular hypertrophy on the electrocardiogram, using a modification of the criteria of Sokolow and Lyon (1949). Positive deflections were measured from the upper border and negative deflections from the lower border of the isoelectric line. Table II shows the precise criteria for the various grades and the number of cases in each grade, the operated cases being denoted by the figures in parentheses. The two exceptions were Case 27, whose electrocardiogram was considered to show severe ischaemic changes, and Case 28, with a Wolff-Parkinson-White syndrome, and these have been excluded from this analysis.

TABLE II

E.C.G. CRITERIA OF LEFT VENTRICULAR HYPERTROPHY

\begin{tabular}{|c|c|c|c|}
\hline $\begin{array}{l}\text { E.C.G. } \\
\text { Grade }\end{array}$ & $R V_{5}+S V_{1}$ & $\begin{array}{l}\text { R S-T Changes in } \\
\text { Leads } V_{5} \text { and } V_{6}\end{array}$ & $\begin{array}{l}\text { No. of } \\
\text { Cases }\end{array}$ \\
\hline $\mathrm{I}^{\dagger}$ & $\begin{array}{l}<35 \mathrm{~mm} . \\
35-45 \mathrm{~mm} .\end{array}$ & $\begin{array}{l}\text { None } \\
\text { None or } \mathrm{S}-\mathrm{T} \text { depres- } \\
\text { sion }<1.5 \mathrm{~mm} \text {. } \\
\text { Flat } \mathrm{T} \text { waves }\end{array}$ & $\begin{array}{l}2(0)^{*} \\
3(0)\end{array}$ \\
\hline $\begin{array}{l}\text { II } \\
\text { III } \\
\text { IV }\end{array}$ & $\begin{array}{l}>35 \mathrm{~mm} . \\
>45 \mathrm{~mm} . \\
>80 \mathrm{~mm} .\end{array}$ & $\begin{array}{l}\text { T inversion }<3 \mathrm{~mm} . \\
\mathrm{T} \quad, \quad 3-7, " \\
\mathrm{~T} \quad, \quad>7,\end{array}$ & $\begin{array}{r}8(6) \\
10(9) \\
3(3)\end{array}$ \\
\hline
\end{tabular}

* Operated cases in each grade.

$\dagger$ In Grades 0, I, II, and III, changes of sufficient amplitude in both the sum of $R+S$ and in the $R$ S-T segments were required. In Grade IV changes of sufficient amplitude in either the sum of $\mathbf{R}+\mathbf{S}$ or in the $\mathbf{R} \mathbf{S}-\mathbf{T}$ segments alone were required.

Brachial Systolic UPSTRoke Time.-There was considerable prolongation of the brachial systolic upstroke time in all cases in E.C.G. grades I-IV with two exceptions, Cases 1 and 20 , both having dominant aortic regurgitation. The systolic upstroke time became further prolonged as the grade of left ventricular hypertrophy increased.

EJection Period.-All cases in E.C.G. grades I-IV showed prolongation of the ejection period of similar degree. The ejection period did not lengthen with the more severe grades of left ventricular hypertrophy.

Peak Systolic Gradient.-Fig. 10 shows that there is a direct relationship between the peak systolic gradient and the degree of left ventricular hypertrophy on the electrocardiogram. The two cases with a normal electrocardiogram had no systolic gradient across the aortic valve, and only one of the three cases in E.C.G. grade I had a systolic gradient over $15 \mathrm{~mm}$. Hg. The eight cases in E.C.G. grades III and IV with a peak systolic gradient of more than $100 \mathrm{~mm}$. $\mathrm{Hg}$ had severe aortic stenosis at operation. However, the two cases (Cases 1 and 2) with dominant aortic regurgitation, proved at operation, with a peak systolic gradient of 60 and $100 \mathrm{~mm}$. $\mathrm{Hg}$ were in E.C.G. grades III and II respectively.

Surgical Estimate of Aortic Valve Size.Fig. 10 also compares the surgeon's estimate of the aortic valve size with the degree of left ventricular hypertrophy. It will be seen that the relationship between the size of the valve orifice and the degree of left ventricular hypertrophy is less clear-cut. Cases 1 and 2, with estimated valve sizes of more than $1 \mathrm{sq}$. $\mathrm{cm}$., were considered to have dominant aortic regurgitation. 


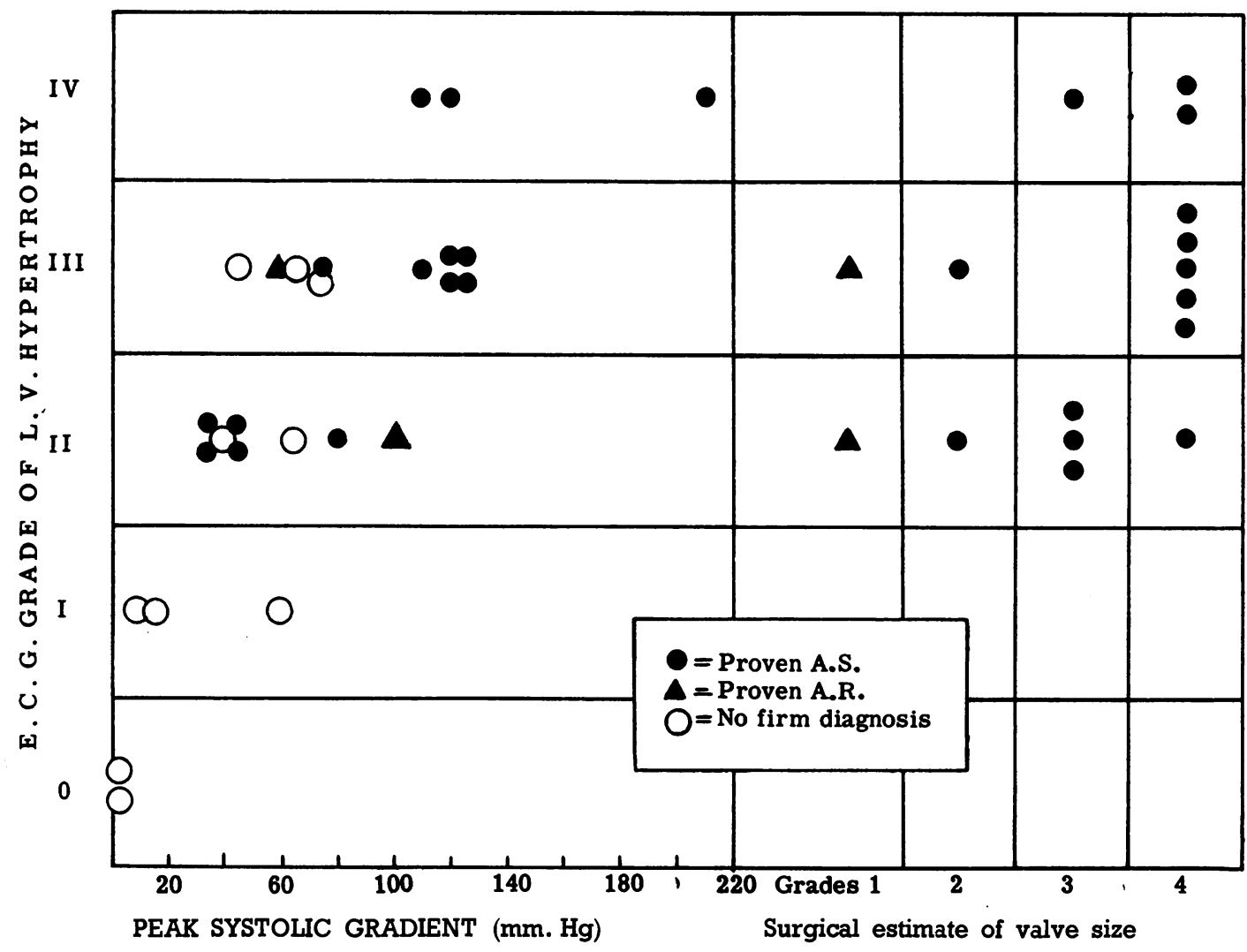

FIG. 10.-Relationship of the E.C.G. grade of left ventricular,hypertrophy to the peak systolic gradient in 26 cases and the surgical estimate of the valve size in 16 operated cases.

\section{CONCLUSIONS}

The left ventricular pressure pulse in aortic stenosis assumes a fairly typical form. Following a moderately raised end-diastolic pressure, the upstroke rises steeply to a high peaked summit with abbreviation of the isometric contraction time and of the phase of rapid ejection. The phase of reduced ejection and the total ejection period are prolonged. The systolic gradient across the aortic valve, combined with the effective left ventricular stroke volume, provides a good index of the degree of obstruction in pure or dominant aortic stenosis. This is shown by the good correlation between the calculated aortic valve area and the surgeon's estimate of the size of the valve orifice. Concomitant aortic regurgitation produces an increase in the total left ventricular stroke volume and therefore a disproportionately high systolic gradient.

All the cases in this series had an abnormally long brachial arterial upstroke time. This change in the peripheral pulse can arise before there is a measurable systolic gradient across the aortic valve and before electrocardiographic evidence of left ventricular hypertrophy has appeared. In more severe degrees of stenosis further prolongation of the upstroke time is found, exceeding twice the normal length in the most severe. Prolongation of the left ventricular ejection period can also be associated with a trivial systolic gradient and minimal electrocardiographic changes, but, unlike the upstroke time, the ejection period is little further prolonged with more severe degrees of $N$ stenosis. Paradoxical splitting of the second heart sound therefore gives no indication of the severity of aortic stenosis. In cases with a systolic gradient $\mathcal{\omega}$ across the aortic valve, the brachial arterial 0 upstroke time is already considerably prolonged and there is maximal lengthening of the ejection period. The height of the systolic gradient increases with increasing degrees of aortic valve obstruction, but variations in stroke volume prevent a close correlation. Pari passu with an increasing systolic gradient, electrocardiographic evidence of left ventricular hypertrophy becomes more marked and we have found a direct 
relationship between the peak systolic gradient and the degree of left ventricular hypertrophy. This might have been expected, because the systolic gradient is dependent upon the size of the valve orifice and the left ventricular stroke volume. It is thus an indirect measurement of the load placed upon the left ventricle. Of the 14 cases in which dominant aortic stenosis was found at operation, five were in E.C.G. grade II, six in grade III, and three in grade IV. We conclude that the degree of left ventricular hypertrophy, as determined by the electrocardiogram, is a reliable indication of the load placed upon the left ventricle in aortic stenosis.

Prolongation of the left ventricular ejection period gives no indication of the severity of aortic stenosis. In contrast, the brachial arterial upstroke time is related to the severity of the lesion and an upstroke time of more than twice normal suggests severe stenosis. Electrocardiographic evidence of left ventricular hypertrophy of grade III severity or more indicates a high aortic systolic gradient and is an absolute indication for aortic valvotomy, provided that significant aortic regurgitation can be excluded. We do not agree with Matthews, Medd, and Gorlin (1955) that severe aortic stenosis can occur with a normal electrocardiogram, and consider that there is no indication for aortic valvotomy in the absence of electrocardiographic evidence of left ventricular hypertrophy.

It is probable that this procedure of direct left ventricular puncture with simultaneous measurement of the cardiac output in aortic stenosis should be reserved for cases in which the clinical evidence of severity is equivocal. It can also be of value in the assessment of aortic stenosis with regurgitation when calculation of the minimal aortic valve area may indicate mild stenosis and, therefore, significant regurgitation.

\section{SUMMARY}

Twenty-eight cases in which a clinical diagnosis of aortic stenosis had been made have been studied by the technique of direct percutaneous left ventricular puncture. Left ventricular and brachial arterial pressure pulses were recorded for measurement of the systolic gradient across the aortic valve: the cardiac output was measured simultaneously in 17 cases.

The features of the left ventricular pressure pulse in aortic stenosis are described in detail.

The peak systolic gradient ranged from 35 to $210 \mathrm{~mm}$. $\mathrm{Hg}$ in the cases of pure or dominant aortic stenosis. In one case of dominant aortic regurgitation, proved at operation, the peak systolic gradient was $100 \mathrm{~mm}$. $\mathbf{H g}$, and the effects of aortic regurgitation on the systolic gradient and other measurements are discussed. However, all the cases with a peak systolic gradient of $120 \mathrm{~mm}$. $\mathrm{Hg}$ or more had dominant aortic stenosis.

Various parameters are compared with the operative assessment of the size of the aortic valve orifice. The calculated aortic valve area and brachial arterial upstroke time are related to the anatomical degree of stenosis.

The electrocardiogram is shown to provide a useful index of the load placed on the left ventricle by aortic stenosis; electrocardiographic evidence of severe left ventricular hypertrophy is regarded as an absolute indication for aortic valvotomy in cases of pure or dominant aortic stenosis.

It is concluded that left ventricular puncture is a satisfactory method of obtaining the systolic gradient across the aortic valve and is valuable in the assessment of difficult cases of aortic valve disease.

We wish to thank Sir Russell Brock and Drs. Charles Baker, Maurice Campbell, and Paul Wood for permiss:on to study patients under their care, and for their encouragement in the development of this procedure. Our thanks are also due to the Photographic Department of the Institute of Diseases of the Chest and the Department of Medical Illustration, Guy's Hospital, for the preparation of the illustrations, to Miss B. Birch, Mrs. P. M. Milne, and Miss M. Richardson for skilled technical assistance, and to Miss E. Marks for secretarial help.

\section{REFERENCES}

Baker, C. G., and Campbell, M. (1956). Lancet, 1, 171

Bergeron, J., Abelmann, W. H., Vazquez-Milan, H., and Ellis, L. B. (1954). Arch. intern. Med., 94, 911.

Björk, V. O., Blakemore, W. S., and Malmström, G. (1954). Amer. Heart $J_{., 48,197 .}$

Brock, R., Milstein, B. B., and Ross, D. N. (1956). Thorax, 11, 163. Buchbinder, W. C., and Katz, L. N. (1949). Proc. Soc. exp. Biol. (N.Y.), 71, 673.

Courtice, F. C., and Douglas, C. G.(1947). J. Physiol (Lond.), 105, 345.

Donald, K. W., and Christie, R. V. (1949). Clin. Sci., 8, 21.

Epps, R. G., and Adler, R. H. (1953). Brit. Heart J., 15, 298.

Fleming, P. R. (1956). Ibid., 18, 569.

Goldberg, H., Bakst, A. A., and Bailey, C. P. (1954). Amer. Heart J., 47, 527.

Gorlin, R., and Gorlin, S. G. (1951). Ibid., 41, 1

- McMillan, I. K. R., Medd, W. E., Matthews, M. B., and Daley, R. (1955). Amer. J. Med., 18, 855.

Gray, I. R. (1956). Brit. Heart J., 18, 21.

Katz, L. N., and Feil, H. S. (1925). Heart, 12, 171

Ralli, E. P., and Cheer, S. (1928). J. clin. Invest., 5, 205.

Kumpe, C. W., and Bean, W.B.(1948). Medicine (Baltimore), 27, 139. Lewes, D. (1951). Brit. med. J., 1, 211.

Macdonald, L., Shanks, J., and Smith, D. W. (1956). Brit. Heart J., $18,568$.

McMillan, I. K. R., Daley, R., and Matthews, M. B. (1952). Ibid., 14,42 .

Matthews, M. B., Medd, W. E., and Gorlin, R. (1955). Brit. med. J., 2, 759 .

Peters, J. P., and Van Slyke, D. D. (1932). Quantitative Clinical Chemistry, Vol. 2. Williams and Wilkins, Baltimore.

Sokolow, M., and Lyon, T. P. (1949). Amer. Heart J., 37, 161.

Wiggers, C. J. (1949). Physiology in Health and Disease, 5th ed., p. 787. Kimpton, London. (1952). Circulatory Dynamics : Grune and Stratton, New York.

Wright, J. L., Toscano-Barboza, E., and Brandenburg, R. O. (1956). Proc. Mayo Clin., 31, 120. 